\title{
Research on the Green Modular Design of the Balcony
}

\author{
Han fang Liü, a , Li qun Guan ${ }^{2, b}$ Bing Kun Liü, c \\ ${ }^{1}$ School of Civil Engineering and Architecture, University of Jinan, Jinan 250022, China \\ ${ }^{2}$ School of Civil Engineering and Architecture, University of Jinan, Jinan 250022, China \\ ${ }^{3}$ School of Civil Engineering and Architecture, University of Jinan, Jinan 250022, China \\ acea_liuhf@ujn.edu.cn, ${ }^{\text {b}} 841729919 @ q q . c o m,{ }^{\circ} 532386650 q q . c o m$
}

Keywords: Green balcony; Energy conversation; Integral; Modularization; Space usage

\begin{abstract}
This paper puts forward the concept of modular design, the green balcony with green cultivation as the theme to the balcony is divided into functions which are simple, easy to create and modify multiple function modules. Thus forming the menu type selection of projects, to provide economic, convenient, and beautiful balcony decoration services. In the design of modular design is to coordinate multiple requirements, implementation system standards, create a diverse and flexible scheme effectively reduce the cost of a method. The idea of modular design to discuss the possibility of balcony space is advantageous to the standardized design, streamline manufacturing and standardization of the management, to give full play to the balcony space and green energy conservation value.
\end{abstract}

\section{Introduction}

With the improvement of modern life standards, people are raising requirement of life quality, people put more attention on living health. In recent years, the increasingly serious environmental pollution and urban ecological deteriorating, low carbon energy saving has become a prerequisite for an ideal living space. To cultivate green plant, energy conservation has become a development trend of architectural space. The feature of green modular design of the balcony is energy conversation. Modular design was based on partition method ${ }^{[1]}$. Design the basic elements of a modular platform which use the basic model, the various types of the model will be effective and reasonable elements in the design of combination, form a combination of flexible modular design system. Modular design can effectively meet the personalized needs of different classes user, based on the modular design of the product is suitable for the standardization of market economy, streamline production. It has strong flexibility and adaptability. The modular design could coordinate multiple requirements, implement system standards, create a diverse and flexible scheme effectively reduce the cost of a method. This paper has a deep discussion of the green modular design of the balcony. On the balcony space, introduced a concept of modular design, provide perfect, convenient, the simple use of green package, so as to realize the balcony afforest of household.

\section{Existing problems}

There are three main problems in the present: Environmental issue; The distance between actuality and ideal living environment; The balcony space did not totally use, and the necessity of the balcony green. 
The environmental problem is one of the main problems in the world nowadays. As the fast development of countries economy around the world, they did not fundamentally solve the pollution of the environment which causes the environmental problem increasingly outstanding. Global warming, ozone depletion, acid rain pollution, land desertification and water crisis, etc. The destruction of the ozone layer and global climate change is a big environmental problem facing the world today. By depletion of the ozone layer phenomenon has been increasing over the earth. By 1994, over the Antarctic ozone depletion area already amounted to $2400^{[2]}$ square kilometers. This number is really making people feel worried. In the face of soaring skyscrapers land scarcity, what can we do?

There is no doubt that green plants are effective way to improve environmental problems. Green plants can increase the oxygen content, improve air quality, keep the humidity of the air, protection of water resources, etc. Green plants are also the basic environment for human beings. Housing is the main place to human to stay, people live in it at least forty percent of the time during their whole life. So the effect about the standard of living environment for all people in the physiology and mental activities always produce the subtle influence is obvious. ${ }^{[3]}$ High quality living environment help people feel better, make body healthy, improve the work efficiency. Good living environment should meet the following conditions: landscape is preferred, good ventilation and a patch of sunshine, if can achieve such a high quality environment in people's own balcony, will become the ideal living space.

Household is decorated in, now for the main function such as kitchen, bathroom, bedroom, sitting room space decoration and utilization have been almost perfect, and the balcony is still a space need to be improved. The balcony space generally is mainly used for planting, flower, or even a small area of the planting some vegetables, etc. But mostly limited to a few potted flower, artificial watering, require people to have a certain amount of time, regular care of potted plant. Therefore, only the families with elderly or person have free time in the home, the balcony will only be used well. In the furniture environment, the balcony is generally has good ventilation, lighting conditions much more enough than other rooms. The balcony is the best choice of green space indoor, have the conditions with abundant sunshine, good ventilation and the growth space to grow plants indoor. Thus, the balcony afforest is very necessary ${ }^{[4]}$

\section{Cause analysis}

Balcony space is not the main reason for the use of the following several aspects : 1 . The negligent consciousness of balcony space use. 2. Lack of perfect products in decorating a system. 3. The rapid pace of modern life make people have no time to deal with this.

Ventilation, day lighting, enjoy the cool, airing clothes, etc, are some of the basic features of the balcony. But beyond that, potted flowers and plants, with vibrant green life ornament, also is the important function of the balcony which cannot ignored.

There are several reasons for the balcony did not make full use of the space. In general, the balcony area is not large, but many people let the balcony sundry accumulated in daily life, let the balcony space constraint, and people neglect the advantage of it. The balcony sunshine, ventilation are forsaken toss aside, became a storage room. To some extent, the room arrangement and function depends on the decoration design, such as kitchen, living room, etc. The furniture guides people what to do in this space. The design of integral kitchen has been widely accepted and approved, which combine sanitation, artistic, safe and convenience. From the streamline design of kitchen counter to store and disinfection which all meet with the function of guidance. The selection 
and use are almost in accordance with the guide of the original design, fully and orderly to the use of space. Nevertheless, the balcony is the lack of such kind of products that a system could lead perfect use of facilities, give person a good use of direction.

In addition, another important reason is that modern life rhythm is too fast, most of the families don't have enough time and some energy to spend on the flowers in the balcony. Most of situation is that they can not reach it, even they hope to. Now common phenomenon is that the old man's family, the balcony can see good vegetation. On the other side, generally young people at home, is a casual placement of a few potted flowers to have basic beautiful decoration effect at best. Time is so precious, so for greening balcony spaces need a convenient, saving-time and systematic solution.

\section{Plan of modular}

With the development of science and technology, the technology of modular technology and its application have been developed greatly in the past few decades in the development of the technology and application of the technology of the modular technology, which is a product design method. To create a good product, be too numerous to enumerate such as IBM360, personal computer etc. Modular product design mode of production and further affect industrial modularization process, and a vast array of modular management ensued. Look around our production and life, there is a model of the mold, from the production module to the enterprise internal organization structure, industrial organization modular, modular not only to help the design of product and organizational structure, but also applied to innovative ways.

Because the module has different combinations to meet the needs of users, and the module has a standard geometry connection interface and a consistent input and output interface. If the division and interface definition of the module is in line with the actual situation of the enterprise, it means that the product is in line with the actual conditions of mass production. In addition, the module realizes the logical separation between the abstract module function and the concrete module. The whole product structure is very clear, easy to understand and design the product from the overall situation, make the technology progress more and more complex engineering management to be improved.

Balcony modular design is the balcony function module processing. According to the above questions, in the balcony decorate, introducing the concept of modular design, can provide a solution. With an example to explain the concept of modular design .Fish has been widely adopted in contemporary house hold, in the living room, office, indoor and outdoor space has been very common. Originally, fish tank is only a tank which people need to change water, clean tank, play oxygen and feeding; any link wrong will affect the fish and appreciation. Therefore, fish-farming is considered to be a trouble, time-consuming, even difficult. At last, aquariums see more rare fish.Now, the aquariums are pleasing to the eyes everywhere. Partly because farming equipment system has been almost perfect. The fish tank with oxygen system, change the water automatically, could control the temperature, and even feed delivery can be done. As the human laborious requires no need anymore, the probability of survival is also improved a $\operatorname{lot}^{[5]}$. It achieved the collectors of simple, easy and convenient system which is widely accepted by the society.

Back to the discussion of the balcony space use, the most important function is creating green. Here young people's family simply put few potted flowers, wasting the sunshine and fresh air. Introducing concept of modular design can be designed to provide a set of perfect modular design scheme of the system. Balcony given green is priority. It can be divided into appreciation type and income type, appreciation is mainly plant beautify flower indoor, to improve living environment; 
Profitability is plant some small kind of fruits and vegetables, for their own consumption. To design a special system for green which could adjustment the temperature, irrigation water, change lightness and put some necessary medicine. That could realize the integration of the interior control, meanwhile, can save time and more convenient for people to use. If it can be produces with industrialization, standardization, and integration, also can get low cost large gain. For different area of the balcony, different types can be appropriate to add some auxiliary functions, such as a study, activity room, etc. enrich the balcony space.

\section{Conclusions}

At first, this paper expounds the origin of the research subject that analyzed the current use of balcony appeared, in order to explore the key, there founded three main problems and discuses the main causes of this phenomenon. Secondly, put forward the necessity of green balcony implementation, then based on the above problems, modular practical method was proposed to realize the green and make full use of the space of the balcony. Then, Focuses on the balcony to green, the fundamental purpose is to improve the environment quality, green balcony main use of the modular, characteristics of the variable.

Finally, focuses on the balcony to green, the fundamental purpose is to improve the environment quality, green balcony main use the characteristics of the variable of modular.

Admittedly, the green balcony design with system, complete and modular can offer consumer a convenient green plan. For the industrialization production, it is easy for commercial operations, at the same time, simply and clearly process of design steps, finally presents a more excellent design results. . Modular method with the concept of green make balcony green and livable.

\section{Acknowledge ments}

This work was financially supported by Humanities and Social Science Research Project of Ministry of Education (13YJA790038) and Humanities and Social Science Research Project of Ministry of Education (13YJAZH087)

\section{References}

[1] Xiumei Li, Jing hen Zhang, "Modular design module row method research", Design and Research, 1001-2265 (2008) 07-0017-05

[2] Xinhua San Diego, in 2004, nova 11 (Reuters), According to the Chilean 9 meteorological bureau's report.

[3] Xiamen Li, Bing Chen, Tian Xing, "Living environment health problems associated analysis method", Building Science, 1002-8528（2014） 02-0041-06

[4] Qiufen Zhou, "Urban balcony greening" of environmental science, Introduction and consulting, 11th, 2005

[5] Shang Miao, modular design thought in the application of industrial product modeling. 